Article

\title{
Loss of SMYD1 Results in Perinatal Lethality via Selective Defects within Myotonic Muscle Descendants
}

\author{
Tara L. Rasmussen ${ }^{1,2}$ and Haley O. Tucker ${ }^{1, *}$ \\ 1 Department of Molecular Biosciences, the University of Texas at Austin, Austin, TX 78712, USA; \\ tara.rasmussen@bcm.edu \\ 2 Department of Molecular Physiology and Biophysics, Baylor College of Medicine, Houston, TX 77030, USA \\ * Correspondence: haleytucker@austin.utexas.edu; Tel.: +1-512-475-7706; Fax: +1-512-475-7707
}

Received: 24 October 2018; Accepted: 14 December 2018; Published: 20 December 2018

check for updates

\begin{abstract}
SET and MYND Domain 1 (SMYD1) is a cardiac and skeletal muscle-specific, histone methyl transferase that is critical for both embryonic and adult heart development and function in both mice and men. We report here that skeletal muscle-specific, myogenin (myoG)-Cre-mediated conditional knockout (CKO) of Smyd1 results in perinatal death. As early as embryonic day 12.5, Smyd1 CKOs exhibit multiple skeletal muscle defects in proliferation, morphology, and gene expression. However, all myotonic descendants are not afflicted equally. Trunk muscles are virtually ablated with excessive accumulation of brown adipose tissue (BAT), forelimb muscles are disorganized and improperly differentiated, but other muscles, such as the masseter, are normal. While expression of major myogenic regulators went unscathed, adaptive and innate immune transcription factors critical for BAT development/physiology were downregulated. Whereas classical mitochondrial BAT accumulation went unscathed following loss of SMYD1, key transcription factors, including PRDM16, UCP-1, and CIDE-a that control skeletal muscle vs. adipose fate, were downregulated. Finally, in rare adults that survive perinatal lethality, SMYD1 controls specification of some, but not all, skeletal muscle fiber-types.
\end{abstract}

Keywords: cardiovascular biology; histone methyl transferase; myogenic regulation; fate determination

\section{Introduction}

Skeletal myogenesis is a critical biological process that is essential for development, regeneration, and homeostasis [1,2]. A number of key transcription factors (TFs) control skeletal muscle development, including regulators of progenitors (e.g., PAX3 and PAX7), regulators of myogenic commitment (e.g., MYF5, MYOD1, and MYF6), and regulators of embryonic myocyte fusion (e.g., MYOG). These and other TFs act as a complex and often compensatory overlapping network to regulate both spatial and temporal expression.

SET and MYND Domain 1 (SMYD1) is a cardiac and skeletal muscle-specific, chromatin-binding factor that regulates growth and morphogenesis during fetal and neonatal development in mice [3,4], humans [5,6], and zebrafish [7,8]. SMYD1 is expressed within the heart and within fast-twitch skeletal muscle cells [3-6]. SMYD1 family members catalyze methylation of histone H3 lysine K4 in vitro, and as initially suggested by Gottlieb et al. [3], act within the developing heart as transcriptional repressors in vivo [4-6]. In some cases [4], SMYD1 inhibits the transcription of target genes by binding directly to target promoters. Alternatively, SMYD1 can serve as a direct target of TFs, including serum response factor (SRF) and MYOG, to direct sarcomere function in vivo [9]. Within sarcomeres, SMYD1 localizes to the M-line, where it physically associates with myosin [10], and within the nucleus, where 
it mediates transcriptional repression. SMYD1 also is expressed in the cytoplasm, where it has been implicated in aspects of adult heart development and oxidative stress [4,11].

SMYD1 is expressed in somitic myoblasts as early as E9.5, and its expression persists throughout myogenesis and into mature myofibers [3,12]. While SMYD1 function in the early developing heart has been well documented [3,5,11], its function in early skeletal myogenesis is less understood. By employing Myf6-Cre, we ablated Smyd1 following myofiber differentiation in skeletal myocytes [12,13]. Mutant mice appeared normal through gestation, but when examined $\sim 6$ weeks postnatally, they exhibited a phenotype similar to non-degenerative myopathy. Defects included physical weakness, myofiber hypotrophy, and a prevalence of oxidative myofibers. While conditional knockout (CKO) mice showed no evidence of re- or degenerating myofibers, they upregulated muscle developmental genes and lost fast-twitch muscle markers.

Since the onset of Myf6-Cre-induced recombination initiates in skeletal muscle at $\sim$ E17.5 and maximizes near birth [14], we sought to address the impact of Smyd1 disruption within the interval between E9.5 and term. Myogenin-Cre (MyoG-Cre) expression can be detected modestly within inter-limb somites at E9.75-E10.75 [15]. From E11.75 onward, Myog-Cre directs increased excision within the trunk as well as proximal and distal limb muscles. By E15.25, deletion covers the dorsal trunk surface and most subcutaneous muscles, albeit mosaic expression of $\mathrm{MyoG}-\mathrm{Cre}$ in hind limb muscle groups has been documented [16].

We report here that skeletal muscle-specific, MyoG-Cre-mediated conditional knockout (CKO) of Smyd1 results almost exclusively in perinatal death, which is unexpected, given only a single previous report of Myog-Cre-mediated lethality [17]. Smyd1 CKOs exhibit multiple skeletal muscle pathologies, but not all myotonic descendants are afflicted equally. While expression of Muscle Regulatory Factors (MRFs) and other previously observed transcriptional regulators were unaffected, TFs controlling adaptive and innate immune processes underlying BAT development/physiology as well as PRDM16, a TF that determines muscle vs. adipose fate, were deregulated. In rare Smyd1 CKO adults that survived perinatal lethality, muscle fiber type specification was perturbed. These findings further expand the breadth and scope of SMYD1 methyltransferase function in skeletal muscle biology.

\section{Methods and Materials}

\subsection{Generation of Myog-Cre/Smydf flox Mice}

All protocols involving animals conformed to the NIH Guide for the Care and Use of Laboratory Animals and were approved by the University of Texas Animal Research Committee (Institutional Animal Care and Use Committee, \#AUP-2010-00097; NIH Assurance \#A4107-01). Smyd1flox mice were generated as detailed by Gottlieb et al. [3], as summarized below.

\subsection{Mating Scheme}

MyoG-Cre mice were provided by Dr. Eric Olson as F1 first generation hybrids of $\mathrm{C} 3 \mathrm{H}$ and C57BL/6J. Recombination induced by MyoG-Cre is initiated in anterior somites at E9.0, and by E9.5, expression is detected in all somites and is confined and maintained in muscle tissue throughout embryogenesis and into adulthood [18]. The same breeding scheme as described previously [3] was employed to create Smyd1 ${ }^{\text {Flox/KO}} ; \mathrm{MyoG}^{-\mathrm{Cr} e^{+/-}}$mice (BL6.FVB.129.C3H hybrids) as well as

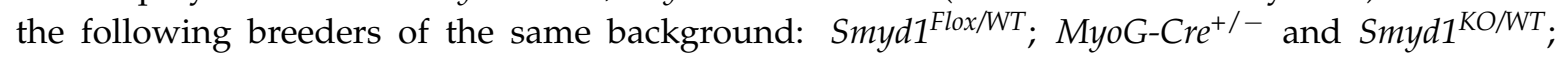
MyoG-Cre ${ }^{+-}$. However, in order to avoid breeding Cre to homozygosity, we began crossing the above genotypes with Cre-negative mice harboring the $S m y d 1^{F l o x}$ and $S m y d 1^{K O}$ alleles. It later became apparent that Smyd1 $1^{\text {Flox/Flox }} ; \mathrm{MyoG}-\mathrm{Cre}^{+/-}$and Smyd1 ${ }^{\mathrm{Flox} / \mathrm{KO}} ; \mathrm{MyoG}-\mathrm{Cre}^{+/-}$displayed the same phenotype. In order to simplify the number of genotypes created and to create higher numbers

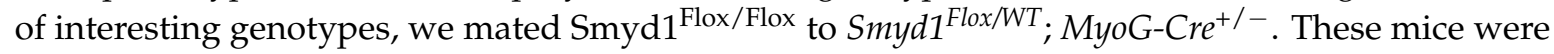
only crossed to one another, thereby maintaining an inbred, but non-isogenic, hybrid population that was similar, but isolated, from the other Cre-induced CKO lines. 


\subsection{PCR Genotyping}

At weaning, each mouse was given a unique ear punch and a short piece of tail $(2-5 \mathrm{~mm})$ was biopsied. The tail tissue was cooked overnight at $55-60{ }^{\circ} \mathrm{C}$ in $200 \mu \mathrm{L}$ tail PCR buffer $(50 \mathrm{mM}$ $\mathrm{KCl}, 10 \mathrm{mM}$ Tris ( $\mathrm{pH} 8.3$ ), $2.5 \mathrm{mM} \mathrm{MgCl} 2,0.1 \mathrm{mg} / \mathrm{mL}$ gelatin, $0.45 \% v / v \mathrm{NP} 40,0.45 \% v / v$ Tween 20) plus $2 \mu \mathrm{L}$ proteinase $\mathrm{K}(10 \mathrm{mg} / \mathrm{mL})$, boiled for $5 \mathrm{~min}$, and centrifuged for $10 \mathrm{~min}$. PCR conditions were as follows: Step $1-94{ }^{\circ} \mathrm{C}$ for $5 \mathrm{~min}$; Step $2-94{ }^{\circ} \mathrm{C}$ for $30 \mathrm{~s}$; Step $3-62{ }^{\circ} \mathrm{C}$ for $1 \mathrm{~min}$; Step $4-72{ }^{\circ} \mathrm{C}$ for $1 \mathrm{~min}$; Step 5-repeat Step 229 times; Step 6-72 ${ }^{\circ} \mathrm{C}$ for $7 \mathrm{~min}$; Step $7-4{ }^{\circ} \mathrm{C}$ for storage. The primers for detection of Smyd1 ${ }^{W T}$ and $S m y d 1^{F l o x}$ were: $5^{\prime}$-cacatctttggtgtggtatggc- $3^{\prime}$ and $5^{\prime}$-ctcacttgcgtccagtacttg- $3^{\prime}$ (amplified product, $540 \mathrm{bp}$ and $620 \mathrm{bp}$ ); $5^{\prime}$-gcatacgcacatgtgctcgc- $3^{\prime}$ and $5^{\prime}$-tcatgagatgggcatgagcc- $3^{\prime}$ (432 and $552 \mathrm{bp}$ ); Smyd1 ${ }^{K O}$ Genotyping primers: $5^{\prime}$-tcatgagatgggcatgagcc- $3^{\prime}$ and $5^{\prime}$-gcccggttctttttgtcaagaccga-3' (985bp). Genotyping primers for Cre were: $5^{\prime}$-ggacatgttcagggatcgccaggcg- $3^{\prime}$ and $5^{\prime}$-gcataaccagtgaaacagcattgctg- $3^{\prime}$ (268 bp).

\subsection{Recombination Assays}

Recombination in each cross was determined by PCR genotyping to determine tissue specificity and efficiency of deletion. Heterozygous mice (Smyd1 $\left.1^{F l o x / W T} ; \mathrm{Cre}^{+/-}\right)$were sacrificed and tissues were harvested and then incubated at $55-60^{\circ} \mathrm{C}$ in PCR buffer (50 mM Tris pH 8.0, $100 \mathrm{mM}$ EDTA, $100 \mathrm{mM} \mathrm{NaCl}, 1 \% \mathrm{SDS})$ and $70 \mu \mathrm{L}$ proteinase $\mathrm{K}(10 \mathrm{mg} / \mathrm{mL})$. After complete digestion (16-48 h), samples were phenol/chloroform extracted, aqueous phase extracted and then centrifuged for $15 \mathrm{~min}$. Pellets were washed in $70 \%$ ethanol, then dried and resuspended in water at $37^{\circ} \mathrm{C}$. Aliquots used for genomic PCR were subjected to the following program: Step $1-94{ }^{\circ} \mathrm{C}$ for $5 \mathrm{~min}$; Step $2-94{ }^{\circ} \mathrm{C}$ for $30 \mathrm{~s}$; Step 3-62 ${ }^{\circ} \mathrm{C}$ for $1 \mathrm{~min}$; Step $4-72{ }^{\circ} \mathrm{C} 1 \mathrm{~min}$; Step 5-return to step 2 for 20-30 cycles using primers: $5^{\prime}$-cacatctttggtgtggtatggc- $3^{\prime}$ and $5^{\prime}$-ctcacttgcgtcccagtacttg- $3^{\prime}$ to detect Smyd $1^{W T}$ (540 bp) and Smyd1 ${ }^{\text {Flox }}$ (620 bp), respectively; $5^{\prime}$-tcatgagatgggcatgagcc- $3^{\prime}$ and $5^{\prime}$-gcatacgcacatgtgctcgc- $3^{\prime}$ to detect Smyd $1^{W T}$ (432 bp) and Smyd1 Flox (552 bp), respectively. Smyd1 ${ }^{\text {Floxdel }}$ produced a band of $395 \mathrm{bp}$.

\subsection{In Situ Hybridization}

Embryos at 15.5 days post coitum (dpc) or younger were extracted in DEPC PBS (1 mL DEPC/L, autoclaved) and tail pieces were removed for genotyping. The remainder of the embryo was fixed in at 10 -fold volumes of $4 \%$ paraformaldehyde at $4{ }^{\circ} \mathrm{C}$ on a rotator overnight. Samples were then washed and either stored at $4{ }^{\circ} \mathrm{C}$ or embedded in paraffin for tissue sectioning as previously described [19].

\subsection{Protein/Immunohistochemistry}

Embryos and adult tissues were extracted in PBS and fixed in at least 10-fold volumes of $10 \%$ formalin or 4\% paraformaldehyde at room temperature on a rotator for 24-72 $\mathrm{h}$. Embryos older than $15.5 \mathrm{dpc}$ were skinned before fixation. Tail segments prior to fixation were genotyped. Samples were washed three times for at least $1 \mathrm{~h}$ in PBS and either stored at $4{ }^{\circ} \mathrm{C}$ or prepared for paraffin embedding and tissue sectioning as previously described [19].

\subsection{End-Point RT-PCR}

Trizol homogenates were thawed and RNA was isolated according to the Invitrogen Trizol protocol. For embryonic samples, isopropanol precipitation was supplemented with 5-10 $\mu \mathrm{g}$ of RNAse free glycogen. After drying the RNA pellet, samples were resuspended in $25 \mu \mathrm{L}$ deionized DEPC water and immediately DNase1 treated with $15 \mu \mathrm{L}$ mix D $(2.7 \times$ DNase I buffer (Invitrogen, Carlsbad, CA, USA); 1 U/ $\mu$ L RNaseOut (Invitrogen, Carlsbad, CA, USA); 2 U/ $\mu$ L DNase I (Roche, Indianapolis, IN, USA)) to a final volume of $40 \mu \mathrm{L}$ and incubated at $37^{\circ} \mathrm{C}$ for $1 \mathrm{~h}$. The enzyme was heat inactivated in $4 \mu \mathrm{L}$ of $25 \mathrm{mM}$ EDTA and incubation at $70{ }^{\circ} \mathrm{C}$ for $10 \mathrm{~min}$. RNA quality and concentration were analyzed using a nanodrop spectrophotometer. Samples were boiled for $5 \mathrm{~min}$ and iced for $5 \mathrm{~min}$ before adding $13 \mu \mathrm{L}$ of mix $2(3.8 \times 1$ st Strand Buffer, $20 \mathrm{mM}$ DTT, $1 \mathrm{U} / \mu \mathrm{L}$ RNaseOut (Invitrogen, 
Carlsbad, CA, USA)). After pre-warming the reaction mixture for 2 min at $37^{\circ} \mathrm{C}, 2 \mu \mathrm{L}$ of $200 \mathrm{U} / \mu \mathrm{L}$ MMLV (Invitrogen, Carlsbad, CA, USA) was added to each reaction except the negative control. Samples were reverse transcribed for $1.5 \mathrm{~h}$ at $37^{\circ} \mathrm{C}$. The enzyme was heat inactivated at $85^{\circ} \mathrm{C}$ for $5 \mathrm{~min}$ and the samples were stored at $4{ }^{\circ} \mathrm{C}$. Next, 1-2 $\mu \mathrm{L}$ of the cDNA reaction were used for RT-PCR with various gene primer sets (Figure S1) or with primers for Smyd1: $5^{\prime}$-ctgcgggcagtgcaagtt- $3^{\prime}$ and $5^{\prime}$-gctcacaggagcagtcaaagtag- $3^{\prime} ; \beta$-actin: $5^{\prime}$-tacgagggctatgctctc- $3^{\prime}$ and $5^{\prime}$-cgcagctcagtaacagtc- $3^{\prime}$.

\section{8. $R T-q P C R$}

Total cellular RNA was isolated using an RNeasy Mini Kit (QIAGEN, Santa Clara, CA, USA). cDNA synthesis was performed with qScript cDNA supermix (Quanta Biosciences, Inc., Denver, CO, USA). RT-qPCRs were performed using PerfeCTa SYBR Green FastMix (Quanta) with $1 \mu \mathrm{L}$ of $20 \times$-diluted cDNA generated from $500 \mathrm{ng}$ of total RNA. RT-qPCR primers were designed to amplify the junction between two exons. Primer sequences for qPCR are listed in Figure S2. Ct values were normalized against GAPDH. qPCR was performed with an initial denaturation step of $10 \mathrm{~min}$ at $95^{\circ} \mathrm{C}$, followed by $15 \mathrm{~s}$ at $95^{\circ} \mathrm{C}$ and $60 \mathrm{~s}$ at $60^{\circ} \mathrm{C}$ for 30 cycles using an MX3000P ${ }^{\mathrm{TM}} \mathrm{QPCR}$ system (Stratagene, La Jolla, CA, USA). The normalized level of a mRNA was determined as $2-\mathrm{Ct}(\mathrm{GOI}) / 2-\mathrm{Ct}(\mathrm{CTL})$, where $\mathrm{Ct}$ is the threshold cycle, GOI is the transcript of interest, and CTL is the housekeeping control (assuming that $\mathrm{Ct}$ is inversely proportional to the initial concentration of mRNA and that the amount of product doubles with every cycle). The statistical significance of RT-qPCR results was determined by two-tailed $t$-test in Microsoft Excel. All sample values were normalized to GAPDH levels (primer sequences noted in Figure S2). GAPDH levels were not significantly altered among different groups (data not shown).

\subsection{RNA In Situ Hybridization}

Embryos were harvested at various pre- and postnatal gestation times, fixed in $4 \%$ paraformaldehyde overnight, and in situ hybridization was performed by whole-mount hybridization as described previously $[3,19]$. Following pre-hybridization procedures, tissue sections were hybridized at $55{ }^{\circ} \mathrm{C}$ with a sense and antisense riboprobe for murine Myogenin. Briefly, RNA antisense $M y o D$ was obtained by RT-PCR after denaturing RNA for $10 \mathrm{~min}$ at $70^{\circ} \mathrm{C}$ in PCR buffer ( $\left.2.5 \mathrm{mM} \mathrm{MgCl} 2\right), 1 \mathrm{mM}$ dNTPs, 50 ng of oligo primer (dT) (Gibco, Carlsbad, CA, USA) and 200 units of the reverse transcriptase enzyme Superscript II (Gibco, Carlsbad, CA, USA). Primers used for the amplifications designed from a combination of the complementary $M y o D$ gene sequence with the T7 bacteriophage promoter sequence in its $5^{\prime}$ end were $5^{\prime}$-agcactacagtggcgactca- $3^{\prime}$ and $5^{\prime}$-ggccgctgtaatccatca- $3^{\prime}$. Hybridization was conducted overnight with antisense and sense probes (Figure S2) using $7.5 \times 10^{5}$ disintegrations per minute (dpm) per slide. The unhybridized probe was removed through stringent washes and treatment with RNase A. Slides were subsequently coated with K.5 nuclear emulsion (Ilford, UK) and exposed at $4{ }^{\circ} \mathrm{C}$ for 12 days. Slides were developed, counter-stained with hematoxylin, and examined using bright and dark field optics.

\section{Results and Discussion}

\subsection{MyoG-Cre Deletion is Specific to Skeletal Muscle}

As described in the Materials and Methods section, we analyzed Cre excision fidelity for genomic DNA recombination of the Smyd1 locus in heterozygous mice. As shown in Figure 1A, there was no detectable deletion of the Flox compared to the wildtype (WT) allele, but efficient recombination was observed specifically within skeletal muscle tissue. 
A.

Tissue

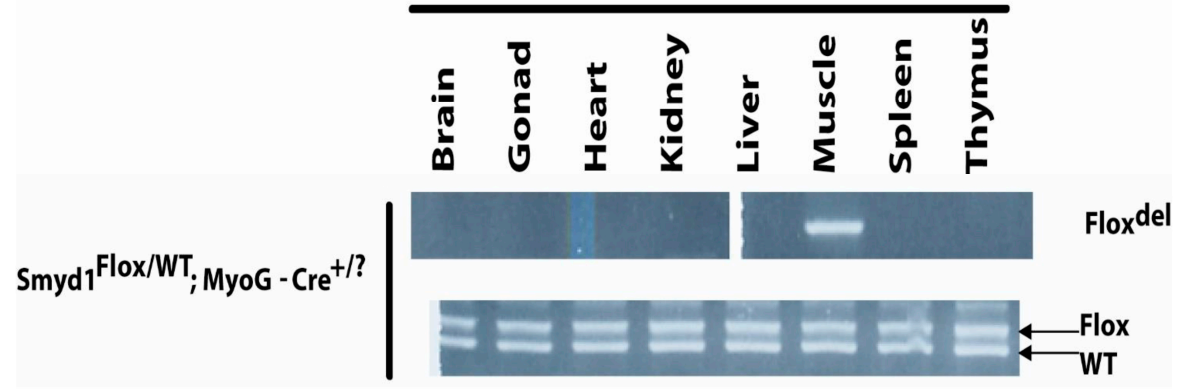

B.

\begin{tabular}{c|c|c} 
Genotype & Expected Ratio & Observed Ratio \\
\hline Smyd1 WT & 0.30 & 0.38 \\
Smyd1 HET & 0.50 & 0.62 \\
Smyd1 MT & 0.20 & 0.00
\end{tabular}

Figure 1. MyoG-Cre deletion of Smyd1 is muscle-specific lethal. (A) MyoG-Cre induces recombination of Smyd1 specifically in muscle. DNA was prepared from the tissues of a heterozygous Smyd1 mice. Recombination was assayed in the upper panel and the positive control Flox/WT assay was assayed in the lower panel. (B) Skeletal muscle-specific Myog-Cre/Smyd1 conditional knockout (CKO) is lethal prior to weaning. Various Smyd1 Flox/KO/WT /MyoG-Cre crosses obtained an N of 350. We expect that $20 \%$ of pups to be homozygous for Smyd1-deficient alleles, $50 \%$ of pups should be heterozygous, and $30 \%$ should be wild type (WT). Litters were genotyped at weaning and the observed numbers were recorded. There was no significant reduction in litter size between birth and weaning.

\subsection{MyoG-Cre-Mediated Smyd1 CKO Results in Perinatal Lethality}

Unexpectedly, of the first 350 pups weaned and genotyped at 3-6 weeks, there were zero Smyd1 conditional knockouts (CKOs; Figure 1B). Dead pups were found during and shortly after birth, but significant numbers of pups did not disappear between postnatal day 1 and weaning. The birth of a few litters was observed. CKO pups were difficult births, probably because of their increased size due to extreme edema. These pups were often crushed during their birthing process. Those that were born intact showed no signs of movement nor breathing.

Genotypic ratios for these litters were analyzed from E9.5 to E17.5, and no significant variance from the expected Mendelian ratios were observed (Table 1). Fetuses were extracted at E18.5-an age at which they could be fostered and survive if viable. However, unlike their littermates, MyoG-Creinduced CKOs at this age made no attempts at locomotion nor breathing. Thus, CKOs were not dying simply due to birthing problems, but never showed signs of life during late stage embryogenesis. Whether or not the heart was pumping at this age was not determined, but without locomotion, these embryos could not survive. 
Table 1. Skeletal muscle-specific SMYD1 CKO does not alter Mendelian ratios prior to birth.

\begin{tabular}{ccccc}
\hline Age (DPC) & Smyd1 MT & Smyd1 HET & Smyd1 WT & Total \\
\hline 9.5 & 5 & 11 & 6 & 22 \\
12.5 & 4 & 9 & 10 & 23 \\
13.5 & 2 & 3 & 3 & 8 \\
14.5 & 0 & 4 & 0 & 4 \\
15.5 & 6 & 11 & 8 & 25 \\
16.5 & 6 & 5 & 2 & 13 \\
17.5 & 2 & 4 & 3 & 9 \\
Total & 25 & 47 & 32 & 104 \\
\hline Expected Ratio & 0.25 & 0.5 & 0.25 & \\
Observed Ratio & 0.24 & 0.45 & 0.31 & \\
\hline
\end{tabular}

WT (Smyd1 WT/Flox/MyoG-Cre) were crossed with MT (Smyd1 WT/KO/MyoG-Cre); HET (both Smyd1 KO/WT and Smyd1 Flox/WTCre). The ratio of MT: HET: WT is summed and shown for all stages.

Therefore, the CKOs are perinatal lethal—a result unanticipated given that only a single previous example of $\mathrm{MyoG-Cre-induced} \mathrm{lethality} \mathrm{had} \mathrm{been} \mathrm{observed} \mathrm{[17].} \mathrm{We} \mathrm{return} \mathrm{to} \mathrm{this} \mathrm{point} \mathrm{in} \mathrm{the} \mathrm{present}$ context below.

\subsection{Skeletal Muscle Development in the MyoG-Cre-Induced Smyd1 CKO is Significantly Derailed}

Viable embryos initially were inspected visually from E11.5 through E18.5 for gross defects. At E12.5, embryos appear normal after sectioning (data not shown). Some embryos were outwardly abnormal as early as E13.5, but by E15.5, CKOs were easily discerned from littermates by eye.

In order to analyze potential skeletal muscle disruption in detail, CKO pups at various embryonic ages were sectioned and compared to their WT littermates. At E14.5, Haematoxylin and Eosin (H\&E)-stained transverse sections of CKOs displayed a marked subcutaneous edema most visible in the cervical region (arrows in Figure 2A and data not shown).

Next, we performed in situ hybridization on transverse sections employing as probe, Myog, which marks all myogenic lineages, on sections prepared at E14.5 (Figure 2B). While the sections are not matched precisely in the rostro-caudal plane, there is a clear reduction of Myog-marked myofiber density in the CKO. However, muscle groups were affected differently. For example, at E15.5, CKO limbs displayed less cellularity than controls, in correspondence with the Myog in situ hybridization (Figure 2B). Unanticipatedly, the pectoralis (white arrow) and sternohyoid muscles (yellow arrow) were no longer visible in sections; i.e., missing entirely (Figure 2B). We also noted that the dorsal muscles (solid blue arrows) were significantly diminished, while other muscles, including the limbs, were clearly less affected. There also appeared to be an excess of brown adipose tissue (blue and white arrows) in the $\mathrm{CKO}$ (Figure 2B and re-addressed below).

Failure of CKO muscular development also can be seen in the H\&E-stained cross-sections of Figure $2 \mathrm{C}$. For example, the scapula region revealed that the surrounding muscle cells were less dense and less organized (Figure 2(Ca-d)). Also, there was an emergence of quite large, multinucleated cells-myoblasts that had fused, but apparently had failed to elongate into myotubes (marked with arrows in Figure 2(Cd)). CKO tongues displayed the same phenotypes as scapula muscles, with evident multinucleated, unfused structures, particularly evident in the CKO tongue (Figure 2(Ch), arrows). However, the masseter muscles appeared totally unscathed from observable morphologic defects (Figure 2(Ci-1)). 

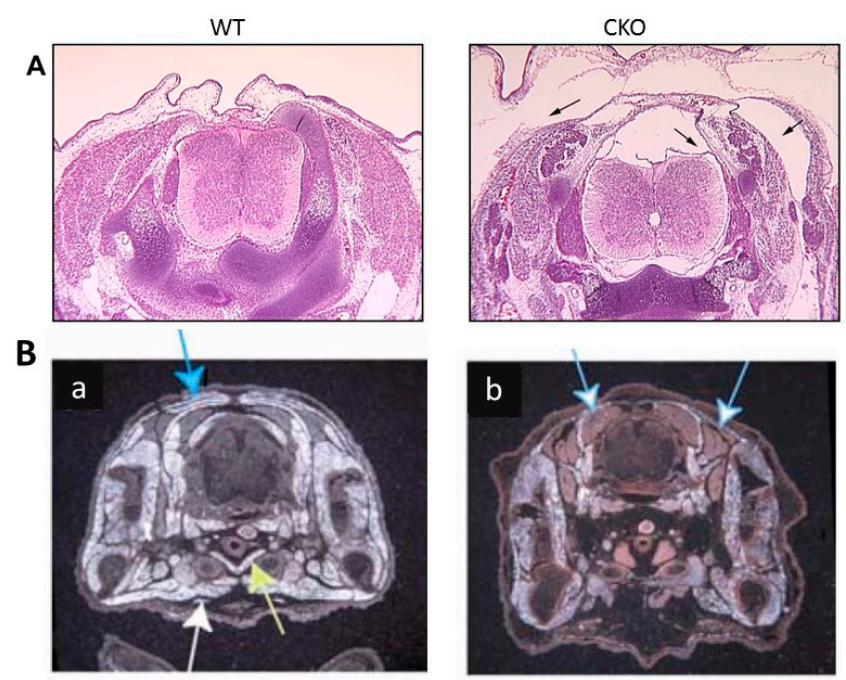

Transverse MyoG in situ

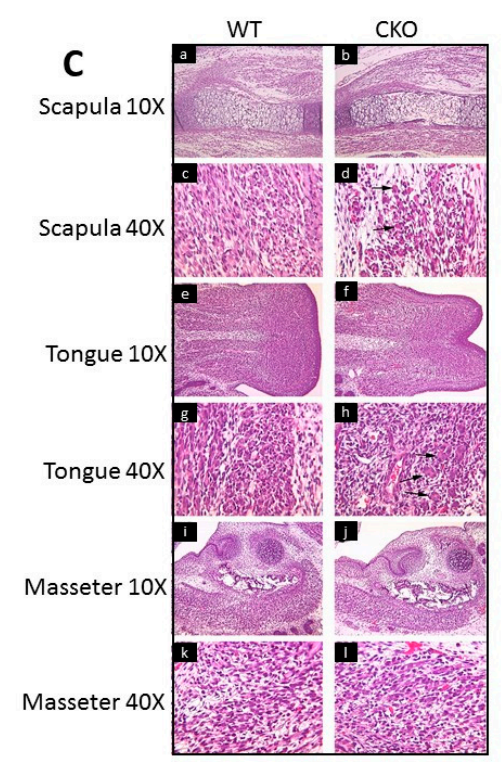

Figure 2. Skeletal muscle development in the MyoG-Cre-induced Smyd1 CKO is significantly derailed. (A) Haematoxylin and Eosin (H\&E)-stained transverse sections of E14.5 WT and CKO embryos stained with H\&E. Marked subcutaneous edema is most visible in the cervical region (arrows). (B) Myogenin in situ hybridization of WT and CKO transverse sections reveal reduction of myocytes and general affliction of some, but not all, muscles. The pectoral (white arrow) and sternohyoid (yellow arrow) muscles did not develop in the CKO; the dorsal muscles (solid blue arrow) are significantly diminished, but other muscles (e.g., limbs) are clearly less afflicted, if at all. There is an excess of tissue tentatively classified as brown adipose tissue (blue and white arrows) in the CKO. (C) H\&E stains (a-h) of WT and CKO sections at E15.5. Scapulae (a-d) show asynchronous elongation and emergence of large, multinucleated cells-myoblasts that did not fuse-but failed to elongate into myotubes (black arrows in $\mathbf{d}$ ). Stains of CKO tongues (e-h) displayed the same phenotypes as above with evident multinucleated, unfused structures (black errors in $\mathbf{h}$ ). CKO masseter muscles (i-l) had no observable morphologic defects.

In summary, SMYD1 skeletal muscle deficiency does not affect all myotonic descendants equally. Trunk muscles are nearly ablated, forelimb muscles are disorganized and improperly differentiated, but some muscles, such as the masseter, are normal. We observed that muscles appear normal as late as E12.5, following post-migration from the somitic myotome (data not shown). However, it is possible that the molecular effect occurred earlier than the visible effect, and Smyd1 is involved in some essential event(s) prior to this migration. Finally, TUNEL staining on sections of WTs and CKOs detected no difference in the number of apoptotic cells (data not shown).

These results along with the increased numbers of large multinucleated cells near areas of reduced cell density suggest that the paucity of myofibers is secondary to degeneration. However, we cannot distinguish whether the myofibers did not form or if they instead underwent rapid degeneration.

\subsection{MyoG-Cre-Induced Smyd1 CKOs Exhibit Proliferative Defects and Non-Autonomous Deposits of Brown Adipose Tissue}

To determine whether the apparent reduction in cellular density is due to a decrease in proliferation, sections were analyzed by immunohistochemistry for Ki67, a protein present in all active, but not in quiescent, stages of the cell cycle [20]. CKO skeletal muscles analyzed at E12.5 showed normal proliferation (data not shown). However, at E14.5, we observed reduction in Ki67 staining in dorsal sections (Figure 3A,B) but not in muscles surrounding the CKO humorous (Figure 3E,F). Notably, the leading edge of proliferation within the CKO tongue epithelium is significantly lagging and appears to be anatomically misshaped (blue arrow in Figure 3D). 


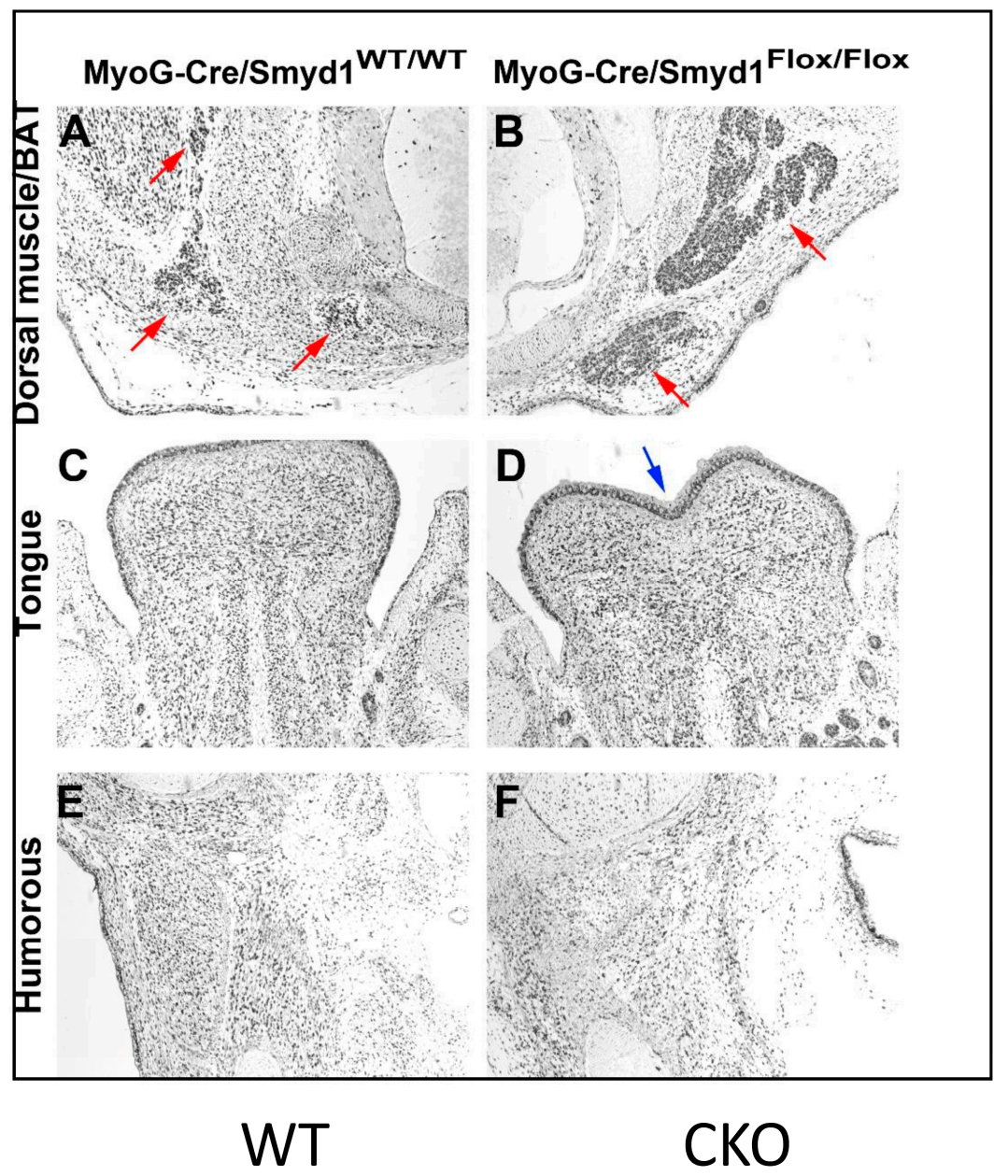

Figure 3. MyoG-Cre-induced Smyd1 CKOs have proliferative defects and non-autonomous deposits of brown adipose tissue. (A,B). Reduced proliferation within E14.5 embryonic tissue and accumulation of brown adipose tissue (BAT, pink arrows) within dorsal muscles as detected by reduced Ki67 staining in CKO. (C,D) Proliferation differences within the epidermal region at the tip of the CKO tongue. The line of proliferation lags in the CKO (D, blue arrow) as compared to WT (C). (E,F) Insignificant proliferative differences within humerus muscles of WT and CKOs.

We suspected that the Ki67 dense regions (particularly evident in CKO dorsal muscle (red arrows)) were fat deposits. Adipocytes can be divided into classes of white (WAT), brown (BAT), or beige cells [21]. We tentatively assigned these adipocytes as "standard" BAT based on: (1) the eosin component of H\&E stain distinguishes WAT from BAT (i.e., eosin colors BAT, but not WAT); (2) unfixed CKO cryostat sections were enriched in deposits staining positively with Sudan Black-a dye specific for BAT (data not shown).

In CKOs, BAT deposits were both increased as well as more heavily stained with H\&E (pink arrows in Figure 3A,B). The CKO BAT area appears to be surrounded by other smaller cells-most likely lymphocytes and other immune cells. BAT composition, function, and numbers undergo significant changes in response to nutritional and mitochondrial demands (readdressed below).

Excess BAT was confirmed in other tissue sections (e.g., Figure 2B,C). Perhaps relevant in this context was our observation that, following shRNA knockdown of SMYD1 in C2C12 myocytes, higher levels of triglycerides-a component of adipose tissue-were apparent (L. Zhu and H.O. Tucker, data not shown). However, a previously considered essential BAT regulator, Prdm16, was downregulated-the opposite effect of that which was predicted (Figure 4). 


\subsection{Skeletal Muscle SMYD1 Deficiency Does not Affect Transcript Levels of Myogenic Regulatory Factors}

In an attempt to identify pathways disrupted by skeletal muscle loss of Smyd1, we analyzed the transcript pool at E12.5 in an attempt to preclude secondary and indirect effects. Because the myogenic program was significantly derailed, we first examined 14 muscle-specific TFs, including the helix-loop-helix regulatory factors (MRFs) MYOG, MYOD1, MYF5, and MYF6 [22]. As shown both by real time RT-qPCR (Figure 4) and by endpoint RT-PCR at E13.5 (Figure S3), no significant changes in expression were observed.
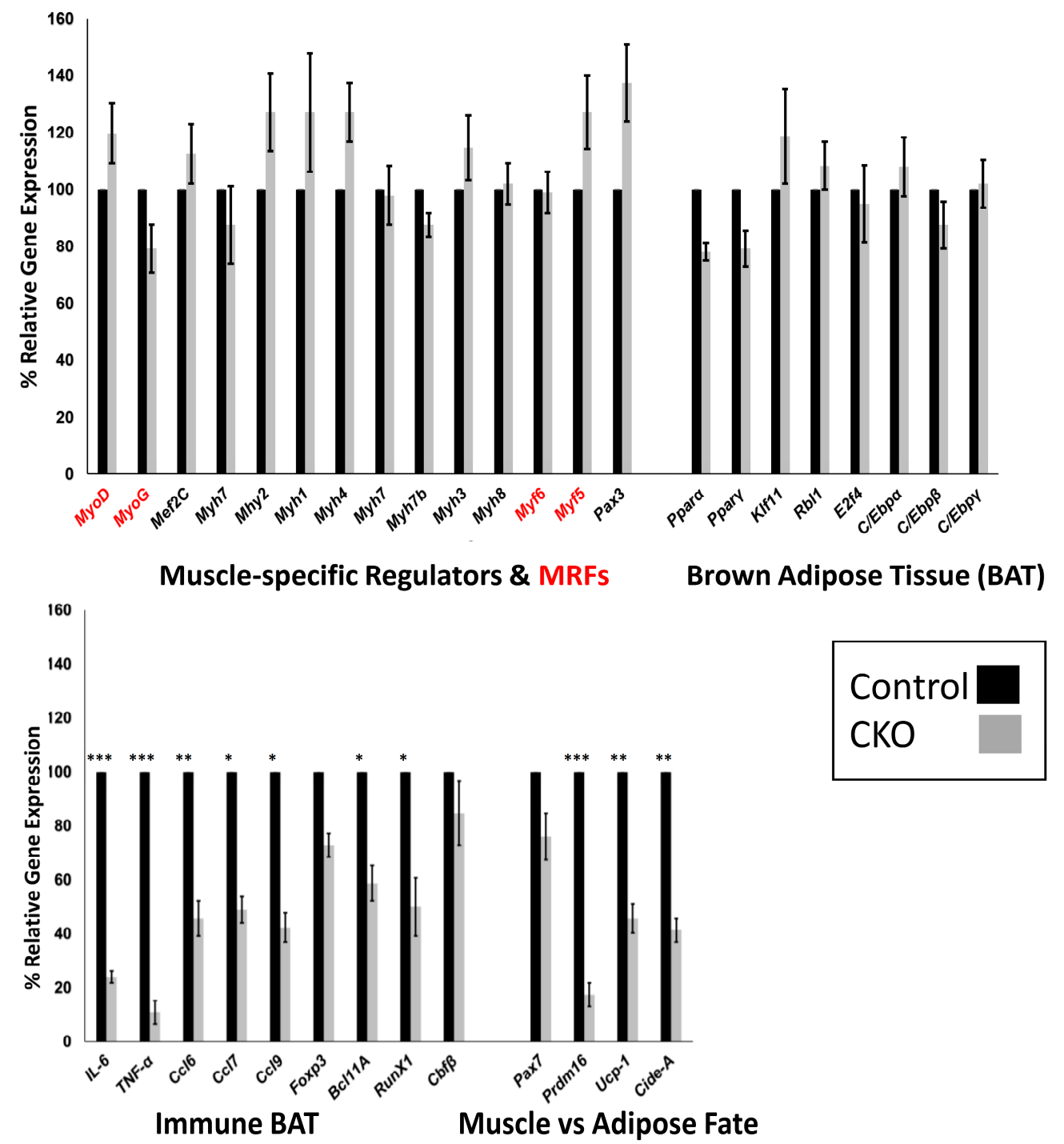

Figure 4. E12.5 Smyd1 skeletal muscle loss results in transcriptional dysregulation of genes required for development of immunologic brown adipose tissue and genes regulating adipose vs. skeletal muscle fate. Transcription of muscle specific regulators (black) including Muscle Regulatory Factors (MRFs) (red) or regulators of conventional brown adipose tissue (BAT) are not altered in Smyd1/MyoD-Cre (CKO) E12.5 embryos. Factors critical to BAT formation within the immune system (Immune BAT) and factors critical to progenitor differentiation to skeletal muscle or adipose tissue (Muscle vs. Adipose Fate) are significantly altered in the CKO relative to WT. E12.5 embryo preparation, RNA preparation, RT-qPCR, and associated analyses were performed as detailed in the Materials and Methods section employing primer-pairs listed in Figure S2. Data from three biological replicates were averaged. Absolute quantification of each target was performed using a standard curve as a reference (Roche Light Cycler software version 1.5, Pleasanton, CA, USA). PCR primers were designed using Primer3 software $[23,24]$. Significance was determined by student's $t$-test as: ${ }^{*} p \leq 0.05 ;{ }^{* *} p \leq 0.01 ;{ }^{* * *} p \leq 0.001$. 
Given the severity of the phenotype, this result was unanticipated. However, MRFs also were not targeted in the only other reported case of Myog-Cre-induced lethality [17]. Instead, the target of Myog-Cre was the Mef2c muscle enhancer, whose lethality occurred perinatally or postnatally (P) depending on genetics [17]. In a C57BL/ 6 mixed background, $100 \%$ lethality was observed at P10, whereas in other backgrounds (e.g., $129 / \mathrm{SvEv}$ ) $50 \%$ of the CKO mice survived. However, the survivors displayed a fiber-type switching phenotype; i.e., myoblasts appeared normal, but differentiation from myoblasts to myotubes was blocked.

The MyoG-Cre:Smyd1 and Mef2c CKOs share a number of similarities. For example, we observed an abundance of primary myogenic cells but also the appearance of large multinucleated (fused) myoblasts that had failed to elongate (Figure 2(B,Cf,j)). This suggested that $\mathrm{CKO}$ myoblasts did not properly differentiate into myotubes - an event controlled to a great extent by MYOD1 and MYOG [22]. However recent reports also have linked similar highly polarized fusion deficiencies to melanoma cell adhesion molecule (MCAM) $[22,25,26]$. MCAM asymmetrically distributes at the tip of elongating myotubes where it colocalizes with actin binding and cell polarity regulators to facilitate directional elongation.

A possible disruption unrelated to MRFs is SMYD1 enzymatic function. SMYD1 is a musclespecific histone methyltransferase [5,27] that is capable of globally altering the transcriptome post-transcriptionally, while yielding no apparent alteration in transcript abundances. This is further evidenced by the lack of gene expression differences in Smyd1 WT and CKOs as determined by microarrays of both E12.5 and E14.5 muscle (T.L.R. and H.O.T; data not shown). Perhaps SMYD1 functions here by posttranslational methylation - an event that has been documented in a number of studies [5,27]. However, there is no evidence that any of the MRFs are methylated nor otherwise posttranslationally modified in a manner which would be catalyzed directly by SMYD1.

\subsection{Central Regulators of BAT are Unaffected by SMYD1 CKO}

A striking phenotypic feature of the MyoG-Cre:Smyd1 CKO was loss of regional BAT (Figures 2B and 3). Transcriptional control of BAT formation has been analyzed extensively [28]. The TFs peroxisome proliferator-activated receptor gamma (PPAR $\gamma)[29,30]$ and the CCAAT/enhancer-binding proteins $(\mathrm{C} / \mathrm{EBP} \alpha / \beta / \delta)[31]$ are essential transcriptional regulatory components that precede the formation of BAT. A downstream consequence of these pathways is de novo mitochondrial biogenesis activation [28].

As shown in Figure 4, RT-qPCR analyses detected no alteration of any of these factors in Smyd1-MyoG CKO muscle relative to controls. Thus, classical mitochondrial BAT biology appears unscathed by loss of SMYD1.

\subsection{SMYD1 Regulates Immune Factors Critical for BAT Development and Physiology}

Alternatively, regulation of BAT metabolism by both the innate and the adaptive arms of the immune system has been well established [32-35]. Recently, the impact and the molecular characterization of BAT-associated T regulatory (Treg) cells have been defined [36]. Several proinflammatory markers are induced by Treg-deficient BAT, including the cytokine interleukin 6 (IL-6), the chemokine ligand 2 (CCL2), and tumor necrosis factor alpha (TNF $\alpha$ ) [37].

As anticipated from those reports, several previously demonstrated Treg-BAT factors were upregulated by SMYD1 loss (Figure 4). These include IL-6, CCL2, TNF $\alpha$, and several additional pro-inflammatory chemokines (CCL6, 7, and 9). Also, as shown previously [36], we observed modest upregulation of Foxp3, the central transcriptional regulator of Treg differentiation, and several of its direct target genes, including BCL11, RUNX1, and CBF $\beta$. Both BCL11 and RUNX1 also have been shown to reciprocally regulate Foxp3 [38].

The relevance of TNF $\alpha$ and IL-6 modulation with respect to muscle biology is particularly striking. $\mathrm{TNF} \alpha$ is essential for incorporating fatty acids into muscle tissue, whereas there is a direct correlation between IL6 and fatty acid oxidation in skeletal muscle [39]. Both are inflammatory cytokines required 
for the maintenance and differentiation of skeletal muscle. TNF $\alpha$ plays a bipolar role in muscle regulation. In its absence, myogenic differentiation is blocked by failure to activate p38 [40]. In contrast the absence of TNF $\alpha$ strongly contributes to cachexia, or wasting atrophy [41]. Overexpression and knockdown experiments have documented that the myogenic markers Myog, $\alpha$-actin, and p21 directly correlate with IL-6 levels [42]. Although TNF $\alpha$ levels are extremely low in SMYD1 CKO muscle (Figure 4), they are not strictly dependent on SMYD1 KD levels (Figure S4). We also observed a tight negative correlation of IL-6 levels with gender at E13.5 (Figure S4).

\subsection{SMYD1 as a Potential Determinant of Muscle vs. Adipose Fate}

Skeletal muscles (slow and fast twitch) and fat tissues (white, beige, and brown) differ broadly in morphology, anatomical locations, transcriptional profiles, and physiologic function [43,44]. BAT and skeletal muscle derive from the same multi-potent progenitors that originate within the central dermomyotome $[45,46]$. Expression of PAX7, an essential multi-potent progenitor TF, is turned off in dermal and BAT but continues to be expressed in MYOD+ embryonic and postnatal muscle progenitors $[47,48]$.

It was shown recently that two MRFs, MyoD and Myf5, act downstream of PAX7 to repress the BAT determining factor, PRDM16, thereby acting as a "molecular switch" to repress BAT fate [48].

To determine if SMYD1 might be a component of this fate-switch circuit, we compared the levels of the above three components in E12.5 WT and CKO embryos. While we observed no effect on PAX7, MYOD nor MYF5, CKO skeletal muscle was depleted of PRDM16-a quintessential requirement for BAT fate choice (Figure 4).

These data suggest that SMYD1 may control muscle vs. adipose fate via modulation of Prdm16 via a pathway different from that described for PAX7. Loss of PRDM16 in adipose tissue results in significant upregulation of thermogenic genes, including the brown fat-uncoupling protein, UCP-1 [49], which previously was touted as a "master regulator" of conventional BAT [28-30], and cell death activator-A (CIDE-A), which controls metabolic rates and higher lipolysis in BAT [50]. Yet as shown in Figure 4, both of these downstream modulators of PRMD16 are downregulated in MyoG-Cre/Smyd1 muscle. This result was the opposite to what would be expected if SMYD1 directly repressed PRDM16, as levels of these direct PRDM16 targets would be upregulated. An alternative mechanism is therefore required.

One possibility is that SMYD1 independently regulates transcription of PRDM16, UCP-1, and CIDE-A. Or, perhaps SMYD1 executes Prdm16 activation via transcriptional or posttranscriptional control. Finally, SMYD1 may mediate cross-talk with adipogenic energy stores or absorption of nutrients. Alternatively, if Smyd1-deficient multipotent progenitors are incapable of signaling the break-down of BAT to release metabolites, BAT would accumulate more efficiently in CKOs than in control embryos.

None of these hypotheses explain why the proliferation marker, Ki67, stained BAT more densely in SMYD1-deficient muscle (Figure 3). One explanation is that while PAX7 is repressed in normal $\mathrm{BAT}$, it continues to be expressed in proliferating muscle progenitor cells in embryonic and young postnatal muscle that give rise to BAT [51,52]. Enlarged BAT foci also have been attributed to increased proliferation and differentiation of brown pre-adipocytes [53]. Alternatively, the observation might have a physiologic explanation. For example, SMYD1-deficient muscle might be unable to efficiently absorb nutrients. In this scenario, excess nutrients within the system could be adsorbed by brown adipose, resulting in abnormal proliferation and expansion of BAT.

\subsection{SMYD1 Controls Specification of Muscle Fiber-Type in Rare Adult Survivors}

After mating and genotyping over 190 litters of MyoG-Cre/Smyd1 mice, we observed no postnatal CKOs on the non-isogenic background described in the Materials and Methods section. However, two of four litters produced by one particular mother-son cross yielded pups in which CKOs survived and appeared outwardly normal into adulthood—albeit not at normal Mendelian ratios (Figure 5A). 


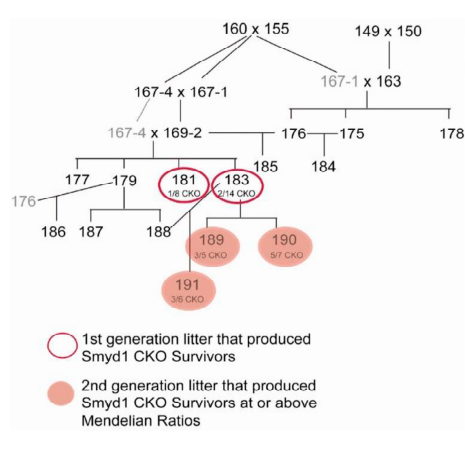

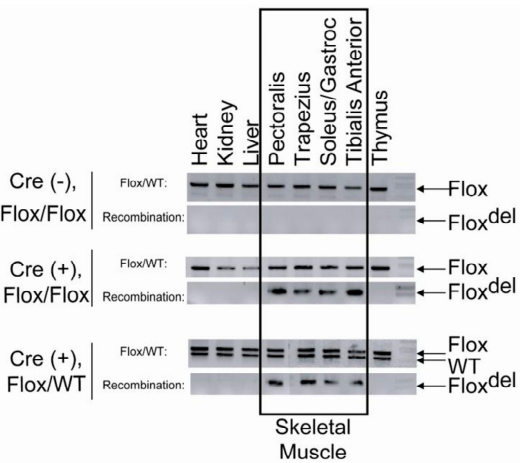

C

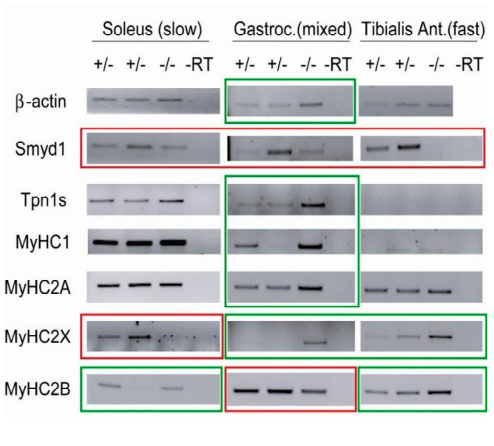

Figure 5. SMYD1 controls specification of muscle fiber-type in rare adult survivors. (A) A heritable change within the Smyd1 locus allowed some MyoG-Cre/Smyd1 (CKO) mice to survive. Mice were bred

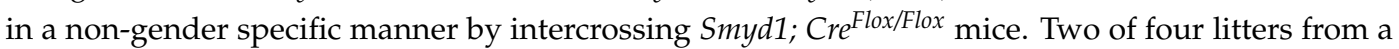
mother-son cross yielded several CKO pups of this genotype. Further crossing of these lines produced CKO pups at or above expected Mendelian ratios. Pups within a litter are indicated in open (first generation) and orange (second generation) circles. Numbers in gray are duplications necessary to show breeding within multiple partners. (B) Recombination occurs specifically within skeletal muscle of MyoG-Cre+Smyd1 $1^{\text {Flox/Flox }}$ (CKO) survivors. Mice were sacrificed, DNA was extracted from their tissues and analyzed via endpoint PCR at postnatal day (P12). Recombination specifically is confirmed as both the Cre transgene and Smyd1 flox allele are present. (C) Slow/fast fiber type composition is altered in adult Smyd1-deficient skeletal muscle survivors. Mice were sacrificed, RNA was prepared and subjected to end-point RT-PCR analysis. Selective isolation of slow vs. fast muscle is indicated by absence of the slow markers, Troponin 1 and MyHC1, in the fast muscles. Heterozygotes express variable levels of SMYD1 (e.g., compare values of all left-side columns to those in the middle). Smyd1 $\mathrm{KO}$ in the soleus muscle is less efficient than in other muscles. Expression levels of MyHC2X and $\mathrm{MyHC2B}$ are altered in all three muscle types. In slow muscle, MyHC2x expression levels directly correlate to those of SMYD1, whereas in mixed (slow + fast) gastrocnemius, MyHC2x is indirectly correlated with SMYD1 levels. MyHC2B levels are indirectly correlated with SMYD1 levels in slow and fast tissues, whereas they are directly correlated in mixed tissue. These results are representative of three independent measurements.

DNA analyses revealed that a muscle-specific recombination event had occurred within the Smyd1 locus. The mutation(s) did affect SMYD1 expression at the RNA level, perhaps because MyoG-Cre expression was lower than in age-matched control embryos (Figure 5B). Because our mouse lines were not isogenic, this particular branch may over time have lost or gained a genetic or epigenetic modification(s) that delayed/reduced Cre expression. If so, the data indicate that SMYD1 is not required for skeletal muscle function per se but is essential for maintaining the development and differentiation of skeletal muscle. This is supported by the Myf6-Cre data reported previously [12,13] and noted below.

Previously unpublished data obtained from shRNA knockdowns of SMYD1 in C2C12 myocytes indicated that SMYD1 repressed Calcineurin $(\mathrm{CaN})$ regulation of slow fiber formation (L. Zhu, personal communication). Consistent with this was our previous observation that SMYD1 forms a stable complex with CaN [54]. We further showed that knockdown of SMYD1 led to dissociation of the complex and activation of CaN-mediated dephosphorylation [54]. However, and in apparent conflict with these conclusions, ablation of Smyd1 postnatally at 6 wk via Myf6-Cre produced mutant mice that exhibited loss of fast-twitch muscle markers [13].

The opportunity afforded by the rare adult MyoG-Cre/Smyd1 skeletal muscle survivors allowed us to address this apparent paradox by providing adequate amounts of dissectible, regional-specific muscle groups of known fiber types. These include the soleus muscle, which is composed primarily of slow muscle fibers; the tibialis anterior, primarily fast muscle fibers; and the gastrocnemius, which is a mixture of the two fiber types $[55,56]$. In skeletal muscle, there are four types of myosin heavy chains: 
a slow oxidative $M y H C 1$, a fast oxidative $M y H C 2 A$, a fast/intermediate $M y H C 2 X$, and a fast glycolytic MYHC2B [55,56].

As shown in Figure 5C, at postnatal day 12 (P12), SMYD1 knockdown was robust within gastrocnemius and within the tibialis anterior muscles, but less effective in the soleus (probably because Cre-expression there was less efficient (Figure 5C). Surprisingly, based on previous observations, we detected no expression of slow muscle markers (MyHC-1 and TPN1S) within CKO fast tibialis anterior muscles, nor in these markers (including MyHCIIA) in either in the tibialis anterior or the soleus. However, glycolytic fast muscle myosin (MyHC-IIB) was upregulated in CKO slow soleus (Figure 5C). Alternatively, intermediate oxidative-glycolytic myosin (MyHC-IIX) was decreased in the slow soleus but increased in the mixed gastrocnemius and fast tibialis anterior fibers of Myog-Cre:Smyd1 CKOs (Figure 5C). These results were confirmed in SMYD1-deficient soleus at P24 both at the RNA level (Figure S5) and at the protein level for a pan antibody against MyHC-IIX that recognizes all slow twitch fibers (Figure S6).

We suspect these phenomena were due to epigenetic silencing, as such, phenomena typically are not "all or none". This is evidenced by the mechanism of reversible methylation, which plays a role in many adaptive processes [57]. In the present context, such a process could lead to incremental decreases in $\mathrm{Cre}$ transgene expression from generation to generation. One might expect such alterations to be both stochastic (i.e., a random percentage acquires a change) and inheritable (i.e., once acquired, reversion is unlikely in subsequent generations).

These data, as with our previous reports [12,13], suggest that loss of SMYD1 results in slow-to-fast transformation of muscle fiber-type in the soleus. Physiologically, loss of slow-twitch, mitochondrial-rich fibers would lead to reduction in oxidative metabolism and greater fatigue. If mitochondrial-rich slow fibers are compromised, Myog-Cre:Smyd1 CKO mice would rely on type $\mathrm{II}^{\mathrm{a}}$ fast fibers to balance this deficiency. Accordingly, $\mathrm{MyHC}^{2 \mathrm{a}}$ and $\mathrm{MyHC}^{2 \mathrm{~b}}$ muscle function should remain unaffected or perhaps even slightly increased on loss of SMYD1. Muscle fiber composition is a critical determinant of the capacity for mitochondrial fuel oxidation, ATP synthesis, and muscle endurance [56,58]. Thus, it would be informative to subject Myog-Cre:Smyd1 adult survivors to treadmill and distance running tests.

\section{Concluding Remarks}

We find it remarkable that SMYD1 deficiency leads to a number of multiple phenotypes dependent on the developmental stage and/or the Cre-recombinase employed for targeting [5-13]. Is there a single fundamental mechanism underlying this apparent heterogeneity? We submit that, yes, the diverse consequences of SMYD1 loss depends upon its bi-functionality as both a lysine (K) and a histone (H) MTase. Further diversification most surely rests on its ability to catalyze multiple histone marks, including $\mathrm{H} 3 \mathrm{~K} 4 \mathrm{~m} 3, \mathrm{H} 3 \mathrm{~K} 4 \mathrm{~m} 2$, and $\mathrm{H} 4 \mathrm{~K} 20 \mathrm{~m} 2$, as well as a growing list (currently up to nine) of confirmed KMTas targets $[4,5]$. While no additional "direct" targets were identified in this report, we judge it very likely that much, if not all, of the transcriptional changes documented in Figure 4 result from protein stabilization or other post-transcription functions. We suggest that identification of additional methylation targets and systematically assigning them into specific developmental stages of heart and skeletal muscle development will be key in establishing the basis for SMYD1-deficient heterogeneity.

While we feel that our study opened another new avenue for SMYD1 research, additional work is required to better interpret the complex phenotype. For example, a systematic histologic time course across each stage of prenatal development needs to be linked to that for full gene expression analyses. At present, results are compromised as only certain stages were analyzed, and there may be some discrepancy between the histology (most penetrant at E14.5) and the gene expression (analyzed primarily at E12.5), since the authors suggest an increase in BAT instead of muscle (at E14.5), but the gene expression shows a decrease in expression of BAT markers, Prdm16 and UCP1, at E12.5. There are 
also lots of data mentioned but not included. A full time course analysis will make it possible to fully interpret what appears to be an interesting and unusual phenotype.

Supplementary Materials: The following are available online at http:/ /www.mdpi.com/2079-9721/7/1/1/s1, Figure S1: RT-PCR primer pairs and conditions. Figure S2: Primer sequences used for qPCR. Figure S3: Skeletal muscle Smyd1 deficiency does not affect transcript levels of Myogenic Regulatory Factors (MRFs). Figure S4: Transcript levels of TNF $\alpha$ and IL6 show gender variation in Smyd1 deficient skeletal muscle. Figure S5: Slow and fast muscle markers are altered. Figure S6: slow muscle fibers are reduced.

Author Contributions: T.L.R. and H.O.T. designed research; T.L.R. performed research; T.L.R. and H.O.T. analyzed data; T.L.R. and H.O.T. wrote the manuscript.

Funding: Support for this work was provided by NIH Grant R01CA31534, Cancer Prevention Research Institute of Texas (CPRIT) Grants RP100612, RP120348; and the Marie Betzner Morrow Centennial Endowment (to H.O.T).

Acknowledgments: We thank Eric Olson for providing MyoG-Cre mice and James Richardson for assistance with in situ hybridization experiments. We thank June Harriss for animal husbandry and Chhaya Das and Maya Ghosh for help in cell culture and molecular techniques. We thank Li Zhu for sharing unpublished data and members of the Tucker lab for discussions and reading of the manuscript. We acknowledge the late Paul Gottlieb in whose lab the project was conceived.

Conflicts of Interest: The authors declare no conflicts of interest.

\section{References}

1. Buckingham, M.; Rigby, P.W. Gene regulatory networks and transcriptional mechanisms that control myogenesis. Dev. Cell 2014, 28, 225-238. [CrossRef]

2. Chal, J.; Pourquié, O. Making muscle: Skeletal myogenesis in vivo and in vitro. Development 2017, 144, 2104-2122. [CrossRef] [PubMed]

3. Gottlieb, P.D.; Pierce, S.A.; Sims, R.J.; Yamagishi, H.; Weihe, E.K.; Harriss, J.V.; Maika, S.D.; Kuziel, W.A.; King, H.L.; Olson, E.N.; et al. Bop encodes a muscle-restricted protein containing MYND and SET domains and is essential for cardiac differentiation and morphogenesis. Nat. Genet. 2002, 31, 25-32. [CrossRef] [PubMed]

4. Franklin, S.; Kimball, T.; Rasmussen, T.L.; Rosa-Garrido, M.; Chen, H.; Tran, T.; Miller, M.R.; Gray, R.; Jiang, S.; Ren, S.; et al. The chromatin-binding protein Smyd1 restricts adult mammalian heart growth. Am. J. Physiol. Heart Circ. Physiol. 2016, 311, H1234-H1247. [CrossRef] [PubMed]

5. Tracy, C.; Warren, J.S.; Szulik, M.; Wang, L.; Garcia, J.; Makaju, A.; Russell, K.; Miller, M.; Franklin, S. The Smyd family of methyltransferases: Role in cardiac and skeletal muscle physiology and pathology. Curr. Opin. Physiol. 2018, 1, 140-152. [CrossRef] [PubMed]

6. Rosa-Garrido, M.; Chapski, D.J.; Vondriska, T.M. Epigenomes in Cardiovascular Disease. Circ. Res. 2018, 122, 1586-1607. [CrossRef] [PubMed]

7. Li, H.; Zhong, Y.; Wang, Z.; Gao, J.; Xu, J.; Chu, W.; Zhang, J.; Fang, S.; Du, S.J. Smyd1b is required for skeletal and cardiac muscle function in zebrafish. Mol. Biol. Cell 2013, 24, 3511-3521. [CrossRef] [PubMed]

8. Tan, X.; Rotllant, J.; Li, H.; De Deyne, P.; Du, S.J. SmyD1, a histone methyltransferase, is required for myofibril organization and muscle contraction in zebrafish embryos. Proc. Natl. Acad. Sci. USA 2006, 103, 2713-2718. [CrossRef] [PubMed]

9. Li, D.; Niu, Z.; Yu, W.; Qian, Y.; Wang, Q.; Li, Q.; Yi, Z.; Luo, J.; Wu, X.; Wang, Y.; et al. SMYD1, the myogenic activator, is a direct target of serum response factor and myogenin. Nucl. Acids Res. 2009, 37, 7059-7071. [CrossRef]

10. Fishman, M.C.; Katus, H.A.; Strähle, U.; Rottbauer, W. The myosin-interacting protein SMYD1 is essential for sarcomere organization. J. Cell Sci. 2011, 124, 3127-3136.

11. Rasmussen, T.L.; Ma, Y.; Park, C.Y.; Harriss, J.; Pierce, S.A.; Dekker, J.D.; Valenzuela, N.; Srivastava, D.; Schwartz, R.J.; Stewart, M.D.; et al. Smyd1 facilitates heart development by antagonizing oxidative and ER stress responses. PLOS ONE 2015, 10, e0121765. [CrossRef]

12. Nagandla, H.; Lopez, S.; Yu, W.; Rasmussen, T.L.; Tucker, H.O.; Schwartz, R.J.; Stewart, M.D. Defective myogenesis in the absence of the muscle-specific lysine methyltransferase SMYD1. Dev. Biol. 2016, 410, 86-97. [CrossRef] 
13. Stewart, M.D.; Lopez, S.; Nagandla, H.; Soibam, B.; Benham, A.; Nguyen, J.; Valenzuela, N.; Wu, H.J.; Burns, A.R.; Rasmussen, T.L.; et al. Mouse myofibers lacking the SMYD1 methyltransferase are susceptible to atrophy, internalization of nuclei and myofibrillar disarray. Dis. Model. Mech. 2016, 9, 347-359. [CrossRef] [PubMed]

14. Hinterberger, T.J.; Sassoon, D.A.; Rhodes, S.J.; Konieczny, S.F. Expression of the muscle regulatory factor MRF4 during somite and skeletal myofiber development. Dev. Biol. 1991, 147, 144-156. [CrossRef]

15. Southard, S.; Low, S.; Li, L.; Rozo, M.; Harvey, T.; Fan, C.M.; Lepper, C. A Series of Cre-ERT2 Drivers for Manipulation of the Skeletal Muscle Lineage. Genesis 2014, 52, 759-770. [CrossRef]

16. Sassoon, D.; Lyons, G.; Wright, W.E.; Lin, V.; Lassar, A.; Weintraub, H.; Buckingham, M. Expression of two myogenic regulatory factors myogenin and MyoD1 during mouse embryogenesis. Nature 1989, 341, 303-307. [CrossRef] [PubMed]

17. Potthoff, M.J.; Arnold, M.A.; McAnally, J.; Richardson, J.A.; Bassel-Duby, R.; Olson, E.N. Regulation of skeletal muscle sarcomere integrity and postnatal muscle function by Mef2c. Mol. Cell Biol. 2007, 27, 8143-8151. [CrossRef]

18. Li, S.; Czubryt, M.P.; McAnally, J.; Bassel-Duby, R.; Richardson, J.A.; Wiebel, F.F.; Nordheim, A.; Olson, E.N. Requirement for serum response factor for skeletal muscle growth and maturation revealed by tissue-specific gene deletion in mice. Proc. Natl. Acad. Sci. USA 2005, 102, 1082-1087. [CrossRef]

19. McFadden, D.G.; Charité, J.; Richardson, J.A.; Srivastava, D.; Firulli, A.B.; Olson, E.N. A GATA-dependent right ventricular enhancer controls dHAND transcription in the developing heart. Development 2000, 127, 5331-5341.

20. Traut, W.; Endl, E.; Scholzen, T.; Gerdes, J.; Winking, H. The temporal and spatial distribution of the proliferation associated Ki-67 protein during female and male meiosis. Chromosoma 2002, 111, 156-164. [CrossRef]

21. Rosen, B.E.; Spleigleman, B.M. What we are talking about when we talk about fat. Cell 2013, 156, 20-44. [CrossRef] [PubMed]

22. Zammit, P.S. Function of the myogenic regulatory factors Myf5, MyoD, Myogenin and MRF4 in skeletal muscle, satellite cells and regenerative myogenesis. Semin. Cell Dev. Biol. 2017, 72, 19-32. [CrossRef] [PubMed]

23. Untergasser, A.; Cutcutache, I.; Koressaar, T.; Ye, J.; Faircloth, B.C.; Remm, M.; Rozen, S.G. Primer3-New capabilities and interfaces. Nucl. Acids Res. 2012, 40, e115. [CrossRef] [PubMed]

24. Koressaar, T.; Remm, M. Enhancements and modifications of primer design program Primer3. Bioinformatics 2007, 23, 1289-1291. [CrossRef] [PubMed]

25. Moreno-Fortuny, A.; Bragg, L.; Cossu, G.; Roostalu, U. MCAM contributes to the establishment of cell autonomous polarity in myogenic and chondrogenic differentiation. Biol. Open 2017, 6, 1592-1601. [CrossRef] [PubMed]

26. Gao, Q.; Zhang, J.; Wang, X.; Liu, Y.; He, R.; Liu, X.; Wang, F.; Feng, J.; Yang, D.; Wang, Z.; et al. The signaling receptor MCAM coordinates apical-basal polarity and planar cell polarity during morphogenesis. Nat. Commun. 2017, 8, 15279-15284. [CrossRef]

27. Du, S.J.; Tan, X.; Zhang, J. SMYD proteins: Key regulators in skeletal and cardiac muscle development and function. Anat. Rec. 2014, 297, 1650-1662. [CrossRef]

28. Kajimura, S.; Seale, P.; Spiegelman, B.M. Transcriptional control of brown fat development. Cell Metab. 2010, 11, 257-262. [CrossRef] [PubMed]

29. Tontonoz, P.; Hu, E.; Spiegelman, B.M. Stimulation of adipogenesis in fibroblasts by PPAR gamma 2, a lipidactivated transcription factor. Cell 1994, 79, 1147-1156. [CrossRef]

30. Wu, Z.; Puigserver, P.; Spiegelman, B.M. Transcriptional activation of adipogenesis. Curr. Opin. Cell Biol. 1999, 11, 689-694. [CrossRef]

31. Kajimura, S.; Seale, P.; Kubota, K.; Lunsford, E.; Frangioni, J.V.; Gygi, S.P.; Spiegelman, B.M. Initiation of myoblast to brown fat switch by a PRDM16-C/EBP-beta transcriptional complex. Nature 2009, 460, 1154-1158. [CrossRef] [PubMed]

32. Ehei, A.; Medrikova, D.; Herzig, S. Immune cells and metabolic dysfunction. Semin. Immunopathol. 2011, 36, 13-25. 
33. Nguyen, K.D.; Qiu, Y.; Cui, X.; Goh, Y.P.; Mwangi, J.; David, T.; Chawla, A. Alternatively activated macrophages produce catecholamines to sustain adaptive thermogenesis. Nature 2011, 480, 104-108. [CrossRef] [PubMed]

34. Lee, Y.H.; Thacker, R.I.; Hall, B.E.; Kong, R.; Granneman, J.G. Exploring the activated adipogenic niche: Interactions of macrophages and adipocyte progenitors. Cell Cycle 2014, 13, 184-190. [CrossRef] [PubMed]

35. Qiu, Y.; Nguyen, K.D.; Odegaard, J.I.; Cui, X.; Tian, X.; Locksley, R.M.; Chawla, A. Eosinophils and type 2 cytokine signaling in macrophages orchestrate development of functional beige fat. Cell 2014, 157, 1292-1308. [CrossRef]

36. Kalin, S.; Becker, M.; Ott, V.B.; Serr, I.; Hosp, F.; Mollah, M.M.; Keipert, S.; Lamp, D.; Rohner-Jeanrenaud, F.; Flynn, V.K.; et al. A Stat6/Pten axis links regulatory T cells with adipose tissue function. Cell Metab. 2017, 26, 475-492. [CrossRef]

37. Medrikova, D.; Sijmonsma, T.P.; Sowodniok, K.; Richards, D.M.; Delacher, M.; Sticht, C.; Gretz, N.; Schafmeier, T.; Feuerer, M.; Herzig, S. Brown adipose tissue harbors a distinct sub-population of regulatory T cells. PLoS ONE 2015, 10, E0118534. [CrossRef] [PubMed]

38. Rudra, D.; Egawa, T.; Chong, M.M.W.; Treuting, P.; Littman, D.R.; Rudensky, A.Y. Runx-CBF $\beta$ complexes control Foxp3 expression in regulatory T cells. Nat. Immunol. 2009, 10, 1170-1177. [CrossRef]

39. Bruce, C.R.; Dyck, D.J. Cytokine regulation of skeletal muscle fatty acid metabolism: Effect of interleukin-6 and tumor necrosis factor-alpha. Am. J. Physiol. Endocrinol. Metab. 2004, 287, E616-E621. [CrossRef]

40. Chen, S.E.; Jin, B.; Li, Y.P. TNF-alpha regulates myogenesis and muscle regeneration by activating p38 MAPK. Am. J. Physiol. Cell Physiol. 2007, 292, 1660-1671. [CrossRef]

41. Kandarian, S.C.; Jackman, R.W. Intracellular signaling during skeletal muscle atrophy. Muscle Nerve 2006, 33, 155-165. [CrossRef]

42. Baeza-Raja, B.; Munoz-Canoves, P. p38 MAPK-induced nuclear factor-kappa B activity is required for skeletal muscle differentiation: Role of interleukin-6. Mol. Biol. Cell 2004, 15, 2013-2026. [CrossRef]

43. Peirce, V.; Carobbio, S.; Vidal-Puig, A. The different shades of fat. Nature 2014, 510, 76-83. [CrossRef]

44. Schiaffino, S.; Reggiani, C. Fiber types in mammalian skeletal muscles. Physiol. Rev. 2011, 91, 1447-1531. [CrossRef]

45. Atit, R.; Sgaier, S.K.; Mohamed, O.A.; Taketo, M.M.; Dufort, D.; Joyner, A.L.; Niswander, L.; Conlon, R.A. Beta-catenin activation is necessary and sufficient to specify the dorsal dermal fate in the mouse. Dev. Biol. 2006, 296, 164-176. [CrossRef]

46. Ben-Yair, R.; Kalcheim, C. Lineage analysis of the avian dermomyotome sheet reveals the existence of single cells with both dermal and muscle progenitor fates. Development 2005, 132, 689-701. [CrossRef] [PubMed]

47. Lepper, C.; Fan, C.M. Inducible lineage tracing of Pax7-descendant cells reveals embryonic origin of adult satellite cells. Genesis 2010, 48, 424-436. [CrossRef] [PubMed]

48. An, G.; Wang, G.; Diao, Y.; Long, Y.; Fu, X.; Weng, M.; Zhou, L.; Sun, K.; Cheung, T.H.; Ip, N.Y.; et al. A molecular switch regulating cell fate choice between muscle progenitor cells and Brown adipocytes. Dev. Cell 2017, 41, 382-391. [CrossRef] [PubMed]

49. Buckingham, M.; Relaix, F. PAX3 and PAX7 as upstream regulators of myogenesis. Semin. Cell Dev. Biol. 2015, 44, 115-125. [CrossRef] [PubMed]

50. Feldmann, H.M.; Golozoubova, V.; Cannon, B.; Nedergaard, J. UCP1 ablation induces obesity and abolishes diet-induced thermogenesis in mice exempt from thermal stress by living at thermoneutrality. Cell Metab. 2009, 9, 203-209. [CrossRef]

51. Abreu-Vieira, G.; Fischer, A.W.; Mattsson, C.; De Jong, J.M.; Shabalina, I.G.; Rydén, M.; Laurencikiene, J.; Arner, P.; Cannon, B.; Nedergaard, J.; et al. Cidea improves the metabolic profile through expansion of adipose tissue. Nat. Commun. 2015, 6, 7433-7439. [CrossRef] [PubMed]

52. Kalcheim, C. Epithelial-mesenchymal transitions during neural crest and somite development. J. Clin. Med. 2016, 5, 1. [CrossRef]

53. Borensztein, M.; Viengchareun, S.; Montarras, D.; Journot, L.; Binart, N.; Lombès, M.; Dandolo, L. Double Myod and Igf2 inactivation promotes brown adipose tissue development by increasing Prdm16 expression. FASEB J. 2012, 26, 4584-4591. [CrossRef] [PubMed]

54. Nie, H.; Rathbun, G.; Tucker, H. Smyd1C Mediates CD8 T Cell Death via Regulation of Bcl2-Mediated Restriction of outer Mitochondrial Membrane Integrity. J. Cell Signal. 2017, 3, 163-173. [CrossRef] 
55. Agbulut, O.; Noirez, P.; Beaumont, F.; Butler-Browne, G. Myosin heavy chain isoforms in postnatal muscle development of mice. Biol. Cell 2003, 95, 399-406. [CrossRef]

56. Yan, Z.; Okutsu, M.; Akhtar, Y.N.; Lira, V.A. Regulation of exercise-induced fiber type transformation, mitochondrial biogenesis, and angiogenesis in skeletal muscle. J. Appl. Physiol. 2011, 110, 264-274. [CrossRef] [PubMed]

57. Giuliani, C.; Sazzini, M.; Bacalini, M.G.; Pirazzini, C.; Marasco, E.; Fontanesi, E.; Franceschi, C.; Luiselli, D.; Garagnani, P. Epigenetic variability across human populations: A focus on DNA methylation profiles of the KRTCAP3, MAD1L1 and BRSK2 genes. Genome Biol. Evol. 2016, 8, 2760-2773. [CrossRef] [PubMed]

58. Hawley, J.A.; Holloszy, J.O. Exercise: It's the real thing! Nutr. Rev. 2009, 67, 172-178. [CrossRef] [PubMed]

(C) 2018 by the authors. Licensee MDPI, Basel, Switzerland. This article is an open access article distributed under the terms and conditions of the Creative Commons Attribution (CC BY) license (http://creativecommons.org/licenses/by/4.0/). 